\title{
Opioid prescriptions down but some patients fear doctors now too strict
}

Cite as: CMAJ 2019 May 13;191:E546-7. doi: 10.1503/cmaj.109-5748

Posted on cmajnews.com on Apr. 24, 2019.

$\mathrm{T}$ o help bring the opioid epidemic under control, health care regulators have been issuing stricter guidelines and rules on how and when opioids should be prescribed, and it appears the effort is having some effect. In the United States, the proportion of opioid prescriptions for people who had not used them previously fell by $54 \%$ between 2012 and 2017. The number of doctors who provided first-time opioid prescriptions fell from around 114000 to just over 80000 . But among those doctors, high-risk prescriptions (more than a 3-day supply or more than $50 \mathrm{mg}$ of morphine equivalents per day) remain high.

In Canada, the overall quantity of opioids prescribed, measured as the number of defined daily doses per 1000 population, declined by $18 \%$ between 2012 and 2017. The number of prescriptions per 1000 people also fell slightly.

This decline could be a positive sign, as it indicates doctors are addressing the problem of overprescribing, says Tara Gomes, an epidemiologist and co-leader of the Ontario Drug Policy Research Network. But it is important to look at where that decline is occurring, she adds, to make sure patients are not losing access to medications they need. "If it is because people who were already on high doses of opioids are being cut off, that's not going to lead to decreased harm. However, if the decline is because fewer people are being started on opioids, or started in a more cautious manner, then I do think that is a positive direction for us to be going in."

Some patients with chronic pain are finding it more difficult to obtain pain medication that works for them. Jules Sherred, a freelance writer in Duncan, British Columbia, says the new guideline on opioid prescribing brought in by the physician, who must try every alternative treatment before prescribing opioids, although Sherred had been taking the relatively mild drug for decades without any sign of abuse.

Sherred is on a waiting list for a specialist pain clinic, where physicians have more leeway in prescribing. In the meantime, he must make do with one pill per day.

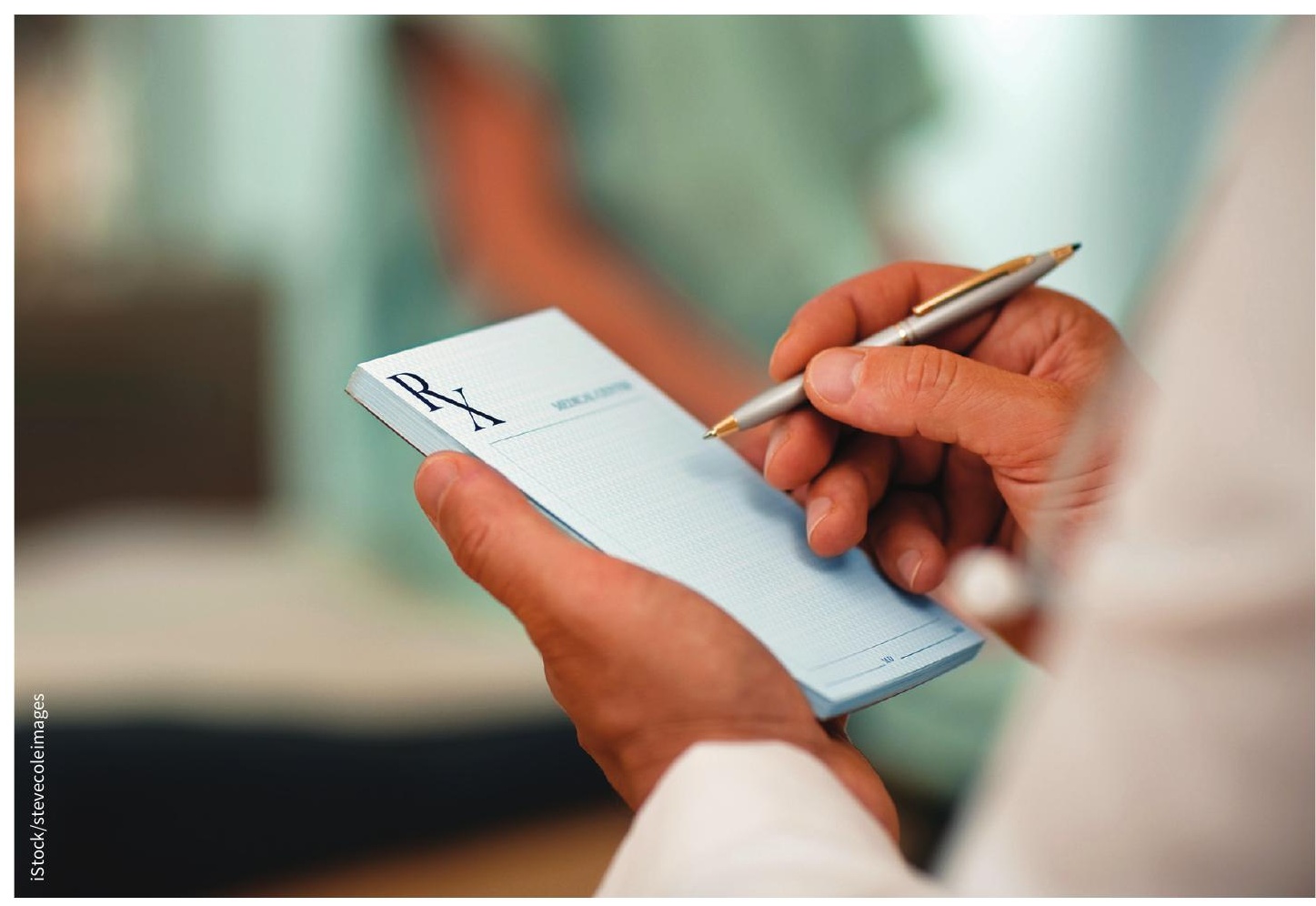

Many doctors have become hesitant to prescribe opioids in recent years.

College of Physicians and Surgeons of BC in 2016 resulted in him being all but cut off from Tylenol with codeine No. 3, which he had been using for 20 years to treat chronic pain from arthritis and lupus. The initial prescription was written by his rheumatologist, but the guideline requires a prescription from his family
"The guidelines were never meant to be enforced so strictly, but a lot of doctors are being cautious because there are no exemptions," he says. "It leaves GPs in a tough place, and a lot of pain patients are suffering."

Gomes has heard similar stories from patients in Ontario, with physicians 
refusing to prescribe the doses previously received by patients or cutting them off entirely. "We're definitely hearing anecdotes that this is happening, but what we don't know is whether it is happening to a small group of people or a broad swath of the chronic pain community," she says.

Patients in the US face similar barriers, says Lisa Reist, an artist in New York City who has been dealing with chronic pain for seven years. The US Centers for Disease Control and Prevention recommended in 2016 that patients without cancer receive no more than $90 \mathrm{mg}$ of morphine equivalents per day. "My doctor felt intense pressure from her bosses and colleagues, no matter how detailed her record keeping or how low a risk I was for substance abuse, to make sure all her patients were below that limit," she says.

Proposed legislation in the US aims to tighten the rules further, by limiting prescriptions to seven days with no refills. The limit would not apply to patients with chronic pain but, given the lack of pain management specialists, Reist fears that would leave many people with undiagnosed and untreated chronic pain.
Aside from the physical danger of suddenly reducing or cutting off access to opioids for patients who have taken them for a long time, there is risk that some patients will turn to the far more dangerous illicit supply, says Matthew Young, a senior research and policy analyst at the Canadian Centre on Substance Use and Addiction. "As we try to reduce prescriptions, we have to be careful not to create a market for illicit opioids," he says. "That's when we will start to see the harms increase."

Brian Owens, St. Stephen, NB 